\title{
SPIRITUALITAS DALAM DOA BAPA KAMI
}

\author{
Nefry Christoffel Benyamin \\ Sekolah Tinggi Theologia Abdiel \\ nefrychris@gmail.com
}

\begin{abstract}
Abstact
Generally, Christian prayer is related to the prayer taught by Jesus Christ, namely the Lord's prayer. Christian community practices the Lord's prayer in their worship, either in their family or in the Church. The question is "Do Christians understand and know the deep meaning of the prayer very well?" This question is important because the prayer talks about the intimate relationship between God and the believers. In this article, the writer tries to scrutinize the spiritual expressions of the prayer and to find the essence of the prayer that describes the manifestation of the believer's love to God.
\end{abstract}

Keywords: Lord's Prayer, Intimacy, Love, Spirituality.

\section{Pendahuluan}

Berdoa adalah suatu tindakan atau kegiatan yang mungkin seringkali dilakukan oleh manusia. Hampir setiap hari seorang manusia yang beragama dan beriman pasti memanjatkan doa dalam kehidupannya. Dalam doa biasanya muncul permohonanpermohonan ataupun sesuatu yang ingin diungkapkan kepada Sang Pencipta. Doa dalam hal ini dipahami sebagai alat komunikasi dengan Tuhan. Dalam doa seorang manusia berbicara dan berinteraksi dengan Tuhannya dan mengharapkan respon atau tanggapan terhadap doanya itu.

Doa biasanya menjadi bagian sentral dalam kehidupan keagamaan dan keberimanan. Tetapi yang menjadi pertanyaan adalah apakah dalam kehidupan keagamaan doa hanya dipahami sebagai sebuah tindakan atau kegiatan di mana seorang manusia mengungkapkan kata-katanya kepada Tuhan, dan bahkan luapan keinginan-keinginannya yang muncul dalam bentuk permohonan. Jika demikian, doa menjadi sesuatu yang tidak ubahnya dengan saat di mana seseorang berbincang-bincang dengan teman-temannya atau keluarganya untuk mengungkapkan apa yang ada dalam pikirannya.

Thomas Aquinas pernah menyampaikan tentang dua macam pengetahuan, yang dalam kaitannya dengan teologi mistik dilihat juga sebagai dua macam doa. ${ }^{1}$ Yang pertama

${ }^{1}$ William Johnston, Teologi Mistik: Ilmu Cinta. (Yogyakarta: Kanisius, 2005), 70. 
adalah pengetahuan yang diperoleh melalui proses penyelidikan ilmiah, di mana itu melalui proses mengalami, memahami dan menilai. ${ }^{2}$ Artinya bahwa pengetahuan itu berasal dari indra luar lalu masuk ke indra dalam dan disampaikan ke akal budi (species impressa/species acquisita). ${ }^{3}$ Yang kedua adalah pengetahuan atau lebih tepat disebut kebijaksanaan adalah anugerah Roh Kudus. Artinya bahwa itu tidak berasal dari indra luar, tetapi langsung dicurahkan (species infusa). ${ }^{4}$ Pengertian yang pertama di atas dalam kaitannya dengan doa dapat dikatakan semacam doa yang berasal dari pengetahuan dan mempengaruhi pemikiran. Jadi, konsep-konsep dan pemahaman-pemahaman yang ada dalam pikiran seseorang sebagai sesuatu yang masuk dari luar itulah yang kadang mempengaruhi doa dalam pemahaman yang pertama ini. Sedangkan yang kedua adalah doa yang timbul dari Roh Kudus sendiri dan bukan hasil pengaruh dari sesuatu yang berasal dari luar. Ini mungkin mirip dengan konsep doa dalam komunitas Taize. Doa bagi komunitas Taize adalah seperti dalam Roma 8:26, "Tetapi Roh sendiri berdoa untuk kita kepada Allah dengan keluhan-keluhan yang tidak terucapkan". 5 Jadi doa dipahami sebagai interaksi langsung dengan Tuhan.

Doa dalam tradisi Kristen pada umumnya dikaitkan dengan doa yang diajarkan oleh Yesus sendiri, yaitu Doa Bapa Kami. Doa Bapa Kami menjadi doa yang umum dipakai dalam kehidupan peribadahan Kristiani, baik di gereja maupun di keluarga-keluarga Kristen. Tetapi apakah Doa Bapa Kami juga hanya menjadi sekadar doa yang umum dipanjatkan oleh orang-orang Kristen ataukah di dalam doa itu ada sesuatu yang lebih mendalam berkaitan dengan hubungan dengan Tuhan. Dalam tulisan ini, akan coba dilihat ungkapan-ungkapan yang bernilai spiritual dalam Doa Bapa Kami dan bagaimana menemukan esensi doa yang menunjukkan hubungan yang mendalam dengan Tuhan (kecintaan kepada Tuhan).

\section{Doa Bapa Kami Sebagai Doa yang Diajarkan oleh Yesus}

Jika membaca Doa Bapa Kami di dalam Alkitab, dapat ditemukan dua versi dari doa tersebut. Yang satu terdapat dalam Matius 6:9-13 dan yang lain dalam Lukas 11:2-4.

\footnotetext{
${ }^{2}$ Ibid.

${ }^{3}$ Ibid.

${ }^{4}$ Ibid.

${ }^{5}$ E. Gerrit Singgih, "Berdoa dan Bekerja, Merenung dan Berjuang: Doa Menurut Tradisi Kristen Calvinisme dan Penghayatannya dalam Kehidupan Kristen di Indonesia”, in E. Gerrit Singgih, Iman \& Politik dalam era Reformasi di Indonesia. (Jakarta: BPK Gunung Mulia, 2000), 197.
} 
Ketika membaca kedua versi tersebut, dapat dilihat ada beberapa perbedaan yang muncul dalam tulisan Matius maupun Lukas. Perbedaan secara struktur dapat dilihat di bawah ini ${ }^{6}$

Matius 6:9-13

Bapa Kami yang di surga

Dikuduskanlah nama-Mu

Datanglah kerajaan-Mu

Jadilah kehendak-Mu

Di bumi seperti di surga

Berilah kami pada hari ini

Makanan kami yang secukupnya

Dan ampunilah kami

Akan kesalahan kami

Seperti kami juga mengampuni

Orang yang

Bersalah kepada kami

Dan janganlah membawa kami

Ke dalam percobaan

Tetapi lepaskanlah kami

Dari pada yang jahat

Karena Engkaulah yang empunya

Kerajaan dan kuasa dan kemuliaan

\section{Lukas 11:2-4}

Bapa,

Dikuduskanlah nama-Mu

Datanglah kerajaan-Mu

Berilah kami setiap hari

Makanan kami yang secukupnya

Dan ampunilah kami

Akan dosa kami

Sebab kami pun mengampuni

Setiap orang yang

Bersalah kepada kami

Dan janganlah membawa kami

Ke dalam percobaan.

Selama-lamanya.

Dengan melihat struktur Doa Bapa Kami antara Matius dan Lukas, terlihat versi Matius jauh lebih panjang daripada versi Lukas. Pada bagian awal doa juga dapat dilihat bahwa Lukas hanya menuliskan Bapa, sedangkan Matius menambahkan Bapa Kami yang di surga. ${ }^{7}$ Pada akhir permohonan pertama, Matius menambahkan "jadilah kehendak-Mu, di bumi seperti di surga". ${ }^{8}$ Pada akhir permohonan kedua, teks Matius jauh lebih panjang

${ }^{6}$ F.X. Agus Suryana Gunadi \& I. Suharyo, Datanglah KerajaanMu: Latar Belakang dan Penafsiran Bapa Kami. (Yogyakarta: Kanisius, 2003), 24-25.

${ }^{7}$ Ibid, 25.

${ }^{8}$ Ibid. 
pula. Lukas hanya menulis "dan janganlah membawa kami ke dalam pencobaan", sementara Matius menambah "tetapi lepaskanlah kami dari pada yang jahat". 9

Tentu perbedaan-perbedaan yang muncul itu karena adanya latar belakang penulisan dan konteks yang berbeda antara Matius dan Lukas. Dalam Matius Doa Bapa Kami ditempatkan dalam bagian Khotbah di Bukit dan dalam konteks Yesus mengajar murid-murid-Nya untuk tidak berdoa seperti orang Farisi. ${ }^{10}$ Kalau membaca dalam Matius, muncul kesan bahwa Yesus menginginkan doa tidak sebagai sesuatu yang dipamerkan atau ditonjolkan kepada orang-orang lain. Yesus malah menginginkan ketika murid-murid-Nya berdoa, mereka perlu mengambil waktu seorang diri untuk berdoa kepada Tuhan. Di sini terlihat adanya unsur untuk menjalin hubungan yang benar-benar intens dengan Tuhan dalam doa. Doa bukan sekadar menunjukkan aktivitas keagamaan atau menunjukkan kesalehan dalam beragama, tetapi doa adalah lebih daripada sekadar itu. Doa adalah perjumpaan dengan Tuhan dan memang sebaiknya adalah ungkapan rasa rindu kita kepada Tuhan.

Dalam Lukas, Doa Bapa Kami diletakkan dalam konteks Yesus mengajar muridmurid-Nya berdoa karena mereka meminta Yesus untuk mengajarkan mereka cara berdoa, di mana permintaan ini berdasarkan pada kebiasaan-kebiasaan kelompok religius lain. ${ }^{11}$ Dari sini muncul kesan bahwa murid-murid minta diajarkan doa karena mereka menginginkan doa yang khas seperti yang mereka lihat pada kelompok-kelompok religius lainnya. Tapi Yesus tentu tidak memaksudkan seperti itu ketika kemudian Dia mengajar Doa Bapa Kami kepada murid-murid-Nya. Kalau membaca lebih lanjut ayat-ayat selanjutnya dalam perikop tersebut, justru ditemukan bahwa Yesus menekankan doa seperti seorang anak yang meminta sesuatu kepada bapanya (Lukas 11:9-13). Permintaan ini secara khusus diterangkan dengan jelas pada ayat ke-13 sebagai permintaan supaya Bapa memberikan Roh Kudus kepada mereka yang meminta. Dengan demikian, sekali lagi dapat dilihat konsep yang mirip dengan apa yang Thomas Aquinas maksudkan dengan macam doa yang kedua di atas. Peran Roh Kudus dalam doa itulah yang ditekankan.

Dari frasa per frasa dalam Doa Bapa Kami ini juga dapat dilihat kekayaan spiritualitas dan nilai-nilai pengajaran Yesus di dalamnya. Bagian pertama dalam Doa Bapa Kami yang berbunyi: "Bapa Kami yang di surga, dikuduskanlah nama-Mu, datanglah Kerajaan-Mu, jadilah kehendak-Mu di bumi dan di surga", menekankan pengakuan akan

\footnotetext{
${ }^{9}$ Ibid.

${ }^{10}$ Lih. Ibid, 27.

${ }^{11}$ Ibid, 28.
} 
Allah yang berkuasa dan kemuliaan nama Tuhan. Pada bagian ini juga dapat dilihat unsur kerinduan supaya kerajaan Allah dinyatakan. Pemberitaan akan kedatangan Kerajaan Allah adalah tema sentral dalam pengajaran Yesus. Kerajaan Allah dapat dimaknai sebagai "pemerintahan Allah" atau "kedaulatan Allah". 12

Dari bagian pertama Doa Bapa Kami ini dapat dipelajari bagaimana dalam doa manusia seharusnya sadar akan keberadaan dari siapa doa itu ditujukan. Kita berdoa kepada Allah, yang dalam Doa Bapa Kami disebut dengan panggilan yang mesra "Bapa". Tetapi terkadang dalam doa kita melupakan hal ini. Kita tidak menyadari dengan siapakah kita berbicara. Memang dalam banyak doa-doa Kristen seringkali kita mendengar pada awal doa ada seruan akan Allah, ke mana doa itu ditujukan. Tapi seringkali ini juga hanya menjadi sekadar basa-basi atau sapaan yang hampa karena kita lebih terfokus kepada permohonan-permohonan yang kemudian kita sampaikan dalam doa. Akibatnya kita sering mengidentifikasikan Tuhan sebagai "satpam" atau "polisi” (permohonan perlindungan), "pemberi berkat", dan bentuk-bentuk identifikasi yang lain. Kita tidak menyapa Tuhan sebagai ungkapan cinta kita kepada-Nya.

Mungkin inilah yang menyebabkan Meister Eckhart berdoa kepada Tuhan supaya dibebaskan dari Tuhan. ${ }^{13}$ Maksudnya mungkin adalah dibebaskan dari identifikasiidentifikasi Tuhan yang menghalangi kita untuk menyadari keberadaan Tuhan yang sesungguhnya dalam doa kita. "Bagi Eckhart, seorang tidak boleh lekat dengan "Tuhan", tetapi harus menerobos ke dalam "Tuhan di atas Tuhan" semata atau, dalam kata Angelus Silesius, orang "harus bergerak lebih tinggi daripada Tuhan, menuju padang gurun." ${ }^{14}$ Oleh karena itu kesadaran akan dengan siapa kita berbicara dalam doa mutlak perlu. Tanpa itu kita hanya akan bertemu dengan "Tuhan-tuhan" yang kita ciptakan sendiri.

Bagian pertama dalam Doa Bapa Kami ini juga berbicara tentang permohonan supaya kehendak Tuhan-lah yang terjadi. Walaupun frasa “jadilah kehendak-Mu di bumi seperti di surga hanya terdapat dalam versi Matius dan dianggap sebagai ucapan yang bukan berasal dari Yesus sendiri melainkan tambahan yang berasal dari tradisi Kristiani awal atau dari Matius sendiri, frasa ini tetap penting untuk dilihat sebagai bagian dalam Doa Bapa Kami. ${ }^{15}$ Frasa ini mengajak untuk mengutamakan apa yang Allah kehendaki daripada terlalu memfokuskan diri pada permohonan-permohonan yang berisi keinginan-

\footnotetext{
${ }^{12}$ E. Gerrit Singgih, "Keluar dari dunia maya, masuk ke dunia yang sebenarnya: spiritualitas untuk masa kini di Indonesia", makalah yang akan dimuat dalam antologi spiritualitas terbitan Interfidei, 2.

${ }^{13}$ Lih. Syafa'atun Almirzanah, When Mystic Masters Meet: Paradigma Baru dalam Relasi Umat Kristiani-Muslim. (Jakarta: PT Gramedia, 2008), 232.

${ }^{14}$ Ibid, 233.

${ }^{15}$ Gunadi \& Suharyo, 93.
} 
keinginan pribadi semata. Kalau mengingat bahwa Yesus sendiri pernah berdoa di taman Getsemani, ketika Dia akan segera diserahkan kepada orang-orang yang akan menyalibkan-Nya, Dia berdoa agar biar kehendak Bapa-Nya saja yang terjadi dan bukan kehendak-Nya. Ini menunjukkan bahwa Yesus sendiri konsisten dengan doa Bapa Kami yang Ia ajarkan kepada murid-murid-Nya. Yesus sendiri memberi contoh bahwa dalam doa yang terpenting adalah mengutamakan apa yang sebenarnya Allah kehendaki. Ini yang seringkali juga dilupakan, di mana orang cenderung berdoa supaya apa yang ia inginkan itulah yang didengarkan dan dikabulkan Allah.

Bagian kedua dari Doa Bapa Kami, yang berbunyi: "berilah kami pada hari ini makanan kami yang secukupnya, dan ampunilah kesalahan kami, seperti kami juga mengampuni orang yang bersalah kepada kami; dan janganlah membawa kami ke dalam pencobaan, tetapi lepaskanlah kami daripada yang jahat”, berbicara tentang kebutuhankebutuhan manusia seperti: rezeki, pengampunan, dan pembebasan dari pencobaan. ${ }^{16}$ Setelah adanya pengakuan dan kesadaran akan keberadaan Allah sebagai yang berkuasa, seperti yang tertuang dalam bagian pertama Doa Bapa Kami, barulah manusia menyampaikan permohonan-permohonan yang berkaitan dengan kehidupannya seharihari.

Frasa pertama dalam bagian kedua ini dapat berarti akan pemeliharaan Allah akan kehidupan manusia, tetapi juga_dalam kaitannya dengan makna kata "makanan" (roti) — dapat diartikan sebagai partisipasi dalam Kerajaan Allah yang sedang berjalan menuju kepenuhannya. ${ }^{17}$ "Makanan sehari-hari dapat menjadi lambang zaman keselamatan yang penuh kegembiraan, kedamaian, pengampunan, dan relasi harmonis dalam dan dengan Allah". ${ }^{18}$ Artinya bahwa dalam pemeliharaan Allah itu dapat dipahami sebagai partisipasi atau ambil bagiannya manusia dalam perwujudan Kerajaan Allah. Permohonan akan pemeliharaan Allah terhadap kebutuhan hidup sehari-hari secara tidak langsung juga mengingatkan setiap kita akan relasi dua arah antara manusia dan Allah. Manusia tidak hanya sekadar memohon kepada Allah dalam doa, tetapi menyadari permohonan itu sebagai bagian dari jalinan hubungan yang timbal balik dengan Allah. Jadi yang ditekankan bukan pada permohonannya, tetapi relasi dengan Allah.

Frasa kedua pada bagian kedua ini yang berbicara tentang masalah pengampunan, menekankan akan bagaimana manusia seharusnya menyadari keberdosaannya dihadapan

\footnotetext{
${ }^{16}$ Ibid, 98.

${ }^{17}$ Ibid, 103.

${ }^{18}$ Ibid.
} 
Allah dan oleh karena itu ia membutuhkan pengampunan dari Tuhan. Tetapi yang perlu diingat adalah bahwa pengampunan Allah itu terjadi bukan semata karena permohonan manusia agar supaya ia diampuni, tetapi lebih kepada kesediaan Allah untuk mengampuni karena besar kasih setia dan belas kasihan-Nya kepada manusia. ${ }^{19}$ Tetapi itu juga bukan berarti tidak ada peran apa-apa dari pihak kita sebagai manusia, pertobatan yang sungguhsungguh harus muncul dari dalam diri sebagai gambaran adanya kemauan untuk memulihkan hubungan dengan Allah. ${ }^{20}$

Pengampunan dari Allah itu juga berbicara tentang kesediaan manusia untuk mengampuni sesamanya. "Pengampunan Allah yang harus terwujud dalam kesediaan mengampuni sesama, amat menonjol dalam pengajaran-pengajaran Yesus tentang pengampunan". ${ }^{21}$ Artinya ketika seseorang memohon pengampunan atas dosa-dosa dan kesalahannya dihadapan Tuhan, itu tidak lepas dari bagaimana ia juga bersedia mengampuni kesalahan yang diperbuat oleh sesamanya terhadap dirinya. Ini tidak berarti pengampunan dari Allah itu bersyarat. Di atas sudah dikatakan bahwa pengampunan dari Allah itu semata-mata karena besarnya kasih setia dan belas kasih-Nya pada manusia. Tetapi mengampuni sesama adalah perwujudan dari bagaimana seseorang menghargai dan juga memaknai pengampunan yang Allah berikan baginya. Dari ajaran-ajaran Yesus ini jelas dapat ditemui hal-hal yang demikian, seperti juga yang telah dikemukakan di atas. Pentingnya pengampunan ini harus dilihat juga sekali lagi dalam hubungan manusia dengan Tuhan. Tuhan mencintai manusia dan memberikan kesempatan kepada manusia untuk merasakan dan menikmati cinta-Nya itu. Dengan demikian biarlah manusia juga belajar mencintai sesamanya dengan mengampuni mereka sebagai respon cinta Tuhan tadi.

Frasa "janganlah membawa kami ke dalam pencobaan, tetapi lepaskanlah kami daripada yang jahat", memperlihatkan akan kelemahan manusia dan ketidakberdayaan manusia di hadapan Allah. Permohonan seperti ini muncul ketika manusia menyadari keberadaan dirinya yang lemah dan oleh karena itu membutuhkan pertolongan Allah. Ada beberapa kemungkinan dalam mengartikan kata pencobaan dalam konteks Doa Bapa Kami ini: pertama, pencobaan dapat berarti tindakan-tindakan manusia yang salah dalam hidup sehari-hari; kedua, pencobaan juga dapat menunjuk kepada pengejaran terhadap pengikutpengikut Yesus dan penderitaan yang diakibatkannya; dan ketiga, pencobaan dapat diartikan sebagai penderitaan yang akan datang di bumi ketika Allah menyatakan

\footnotetext{
${ }^{19}$ Lih. Ibid, 107.

${ }^{20}$ Ibid.

${ }^{21}$ Ibid.
} 
kemenangan akhir atas segala kekuatan jahat. ${ }^{22}$ Permohonan agar Allah tidak membawa manusia kepada pencobaan menunjukkan kalau manusia itu bergantung sepenuhnya kepada Allah.

Bagian terakhir dari Doa Bapa Kami merupakan sebuah pengakuan akan Allah yang kekal. Pengakuan ini lebih dikenal sebagai doksologi, yang adalah pujian kepada Allah. ${ }^{23}$ Dalam doksologi biasanya ada tiga hal yang menjadi cirinya, yaitu syukur atas penyelenggaraan Allah pada masa lalu sampai sekarang; kepercayaan bahwa Allah masih akan tetap meneruskan karya agung-Nya bagi manusia; dan selanjutnya kepercayaan ini memberi keyakinan dan harapan akan masa depan. ${ }^{24}$ Doksologi ini mengingatkan setiap orang seperti pada awal doa ketika ia mengakui dan menyadari keberadaan Tuhan. Tetapi kalau dilihat doksologi dalam Doa Bapa Kami ini ingin menekankan akan keberadaan Allah yang kekal, yang tidak dibatasi oleh waktu. Bagian ini sekaligus menjadi bagian penutup dalam doa yang sekaligus menjadi pengakuan akan Allah yang akan menyertai kehidupan.

\section{Teologi, Spiritualitas dan Seni dalam Doa Bapa Kami}

Doa Bapa Kami sebagai doa yang diajarkan oleh Yesus kepada murid-murid-Nya telah memainkan peran yang sangat penting dalam kehidupan dan perkembangan doa dalam kekristenan. Doa ini telah mendasari formulasi-formulasi dan teologi-teologi doa yang muncul dan berkembang dalam kekristenan. Doa ini memiliki kekayaan khasanah makna sebagaimana yang sudah kita lihat dalam pembahasan di atas.

Secara teologis, Doa Bapa Kami tentu saja berbicara banyak. Pengakuan dan pemuliaan akan keagungan Allah pada bagian awal doa ini mengingatkan kita akan teologi doa yang memang sebaiknya didasarkan kepada kesadaran akan Allah yang hidup dan dapat dijumpai dalam doa. Demikian pula konsep mengenai Kerajaan Allah yang memainkan peran penting dalam teologi Kristen karena merupakan sentral atau pusat pemberitaan dan pengajaran Yesus hadir pada bagian awal doa ini. Frasa "datanglah kerajaan-Mu" menjadi ungkapan akan kerinduan kehadiran pemerintahan atau kedaulatan Allah dalam kehidupan manusia. Kerajaan Allah itu dirindukan untuk hadir di dunia ini

\footnotetext{
${ }^{22}$ Ibid, 114-115.

${ }^{23}$ Ibid, 120.

24 Ibid.
} 
dan bukan di tempat lain, sehingga dipahami bahwa bukan manusia yang akan datang ke dalam Kerajaan Allah itu, melainkan Kerajaan Allah itulah yang menghampiri manusia. ${ }^{25}$

Konsep tentang pengampunan dan pemeliharaan Allah adalah juga bagian dari nuansa teologis dalam Doa Bapa Kami ini. Bagaimana Yesus sendiri mengajarkan, tidak hanya dalam pengajaran-Nya di tengah-tengah pelayanan-Nya tentang pengampunan dan pemeliharaan Allah ini, tetapi juga dalam doa yang menunjukkan itu adalah sesuatu yang diimani. Pengampunan dan pemeliharaan Allah adalah juga bagian dari pokok-pokok ajaran Kristen.

Sebagai doa, Doa Bapa Kami juga tentu mengandung nilai-nilai spiritualitas dalam kaitan hubungan antara manusia dengan Allah. Dalam Doa Bapa Kami, kita diajar untuk masuk lebih dalam, menghayati keberadaan yang sesungguhnya. Kita diajak untuk datang dalam doa sebagai ungkapan cinta dan kerinduan kita kepada Tuhan. Doa Bapa Kami tidak dimulai dengan seruan permohonan yang berisi kepentingan pribadi kita, tapi dengan ungkapan-ungkapan untuk berfokus kepada Allah Sang Pencipta.

Dengan frasa "jadilah kehendak-Mu" kita diingatkan tentang macam doa yang kedua menurut Thomas Aquinas, bahwa doa adalah dicurahkannya cinta terhadap Allah oleh Roh Kudus. Kita tidak lagi memikirkan pikiran kita sendiri ketika kita meminta Allah yang berkehendak. Pikiran itu mungkin mengganggu kita untuk kita menemukan kobaran cinta Allah. Sebagaimana dikatakan oleh William Johnston, "pengetahuan itu dapat menyakitkan karena manusia tidak senantiasa siap untuk bertemu dengan Yang Ilahi dan dapat terjerumus ke dalam kegelapan oleh berlimpahnya cahaya". ${ }^{26}$ Dengan membiarkan kehendak Allah yang terjadi, manusia membiarkan dirinya ditarik untuk menapaki jalan mistik menuju Allah. ${ }^{27}$ Saya mengulang apa yang sudah dituliskan di atas dalam kaitannya dengan Doa Bapa Kami ini dalam konteks Injil Matius, bahwa doa bukan sekadar menunjukkan aktivitas keagamaan atau menunjukkan kesalehan dalam beragama, tetapi doa adalah lebih daripada sekadar itu. Doa adalah perjumpaan dengan Tuhan dan memang sebaiknya menjadi ungkapan rasa rindu kita kepada Tuhan. Dari Doa Bapa Kami, kita diajak untuk menjalin hubungan dengan Tuhan tanpa terlebih dahulu dipengaruhi oleh pikiran-pikiran kita yang mungkin sudah berisi permohonan ini dan itu sehingga kita kehilangan citarasa dalam doa.

\footnotetext{
${ }^{25}$ Lih. Singgih, "Keluar dari ...", 3.

26 Johnston, 70.
}

${ }^{27}$ Bnd. Ibid, 71 . 
Dari sisi seni, Doa Bapa Kami dapat dikatakan sebuah seni doa. Secara struktur, Doa Bapa Kami juga dapat terlihat terkomposisi dengan baik. Struktur itu dapat dilihat sebagai berikut ${ }^{28}$ :

Seruan Pembukaan: Bapa Kami yang di surga

Bagian Pertama:

- Dikuduskanlah nama-Mu

- Datanglah Kerajaan-Mu

- Jadilah kehendak-Mu di bumi seperti di surga

Bagian Kedua:

- Berilah kami pada hari ini makanan kami yang secukupnya

- Dan ampunilah kesalahan kami, seperti kami juga mengampuni orang yang bersalah kepada kami

- Dan janganlah membawa kami ke dalam pencobaan, tetapi lepaskanlah kami daripada yang jahat

Penutup (Doksologi): Karena Engkaulah yang empunya Kerajaan dan kuasa dan kemuliaan sampai selama-lamanya. Amin.

Dengan melihat struktur di atas kita dapat melihat bagaimana Doa Bapa Kami ini secara sastra terkomposisi dengan baik dan teratur. Di mana Doa Bapa Kami diawali dengan sebuah pembukaan yang merupakan seruan kepada siapa doa itu dipanjatkan. Selanjutnya Doa Bapa Kami dibagi menjadi dua bagian yang masing-masing terdiri dari tiga poin penting dan memiliki kedalaman makna. Kemudian, Doa Bapa Kami diakhiri dengan sebuah bagian penutup yang berisi doksologi atau pengakuan akan kebesaran, kemahakuasaan, dan kemuliaan Allah yang bersifat kekal. Dengan memperhatikan komposisi seperti itu, jelas bahwa doa Bapa Bapa Kami adalah seni doa yang menyentuh baik rasa maupun jiwa manusia yang terdalam, yaitu ketika ia berhubungan dengan pencipta-Nya dalam sebuah ungkapan cinta dan kerinduan kepada Sang Kasih

\section{Kesimpulan}

Doa Bapa Kami sebagai doa yang diajarkan oleh Yesus kepada murid-murid-Nya, benar-benar memiliki kekayaan makna. Kalau diperhatikan dengan baik, doa ini pun mungkin dapat dipakai sebagai aplikasi dalam kehidupan spiritualitas bersama. Karena dari

\footnotetext{
${ }^{28}$ Bnd. Gunadi \& Suharyo, 7-8.
} 
isinya mengandung nilai-nilai yang bisa bersifat universal dan mengutamakan hubungan antara manusia dengan Tuhan, tetapi tidak melupakan juga hubungan manusia dengan manusia lainnya. Paling tidak doa ini mengajarkan kepada kita tentang bagaimana semestinya kita berdoa dan memaknai doa sebagai sebuah hubungan antara Allah dan manusia yang bertemu di dalamnya. Doa hendaklah jangan menjadi semacam rutinitas belaka dalam kehidupan keagamaan dan menyebabkan kehampaan di dalamnya. Tetapi hendaklah doa menjadi saat perjumpaan di antara Pencipta dengan ciptaan-Nya dalam hubungan yang penuh kobaran cinta.

\section{Kepustakaan}

Almirzanah, Syafa'atun. When Mystic Masters Meet: Paradigma Baru dalam Relasi Umat Kristiani-Muslim. Jakarta: PT Gramedia, 2008.

Gunadi, F.X. Agus Suryana \& Suharyo, I. Datanglah KerajaanMu: Latar Belakang dan Penafsiran Bapa Kami. Yogyakarta: Kanisius, 2003.

Johnston, William. Teologi Mistik: Ilmu Cinta. Yogyakarta: Kanisius, 2005.

Singgih, E. Gerrit. "Berdoa dan Bekerja, Merenung dan Berjuang: Doa Menurut Tradisi Kristen Calvinisme dan Penghayatannya dalam Kehidupan Kristen di Indonesia", in Singgih, E. Gerrit. Iman \& Politik dalam era Reformasi di Indonesia. Jakarta: BPK Gunung Mulia, 2000.

"Keluar dari dunia maya, masuk ke dunia yang sebenarnya: spiritualitas untuk masa kini di Indonesia", makalah yang akan dimuat dalam antologi spiritualitas terbitan Interfidei, 2. 